\title{
DETERMINATION OF OIL CONTENT AND PHYSICOCHEMICAL PROPERTIES OF OIL EXTRACTED FROM NIGER SEED OIL GROWN IN GAMO GOFA, SOUTHERN ETHIOPIA
}

\author{
BEZUAYEHU GETACHEW, KEMAL AHMED, MAHMUD ENDRIS, \\ MANALE ZEBENE, TSEGAY HIWOT ${ }^{2^{*}}$ BIRHANE HAILE ${ }^{2^{*}}$ \\ MEBRATU MERESA, MEDHANIT AMANU ${ }^{1 *}$ \\ ${ }^{1} 3^{\text {rd }}$ year Chemistry students, Dilla University, Dilla, Ethiopia \\ ${ }^{2}$ Dilla University, Dilla, Ethiopia
}

Email: tsegayhi@gmail.com

\begin{abstract}
Keyword: Niger seed, Soxhlet extraction, maceration, physicochemical properties, Gamo Gofa, n-hexane and ethyl acetate
\end{abstract}

\begin{abstract}
The Niger seed oil was collected from gamo-gofa, southern part of Ethiopia for oil extraction. The collected seed were oven dried and crushed in to powder by mortar and pestle. A soxhlet and maceration extractions were used for extraction of the oil. The solvents used for both extractions were n-hexane and ethyl acetate. The main reason two different types of solvents and two different type of extraction methods used in this project were to check which type of solvent and extraction method were effective for extraction of oil from Niger seed. From both extraction methods the extracted oil was separated from the solvents by simple distillation. The oil content and the physico-chemical parameters of the oil were determined and an oil content of $23.45 \%$ and $21.35 \%$ were obtained by maceration and $33.02 \%$ and $22.7 \%$ by soxhlet extraction method from nhexane and ethyl acetate respectively. The physico-chemical parameters of the seed and oil were determined and the result shows that moisture content of the seed was $(8.3 \%)$ and acid value of the oil (1.7391), saponification value (6.0308), Kinematic viscosity $\left(0.561 \mathrm{~m}^{2} / \mathrm{s}\right)$, Density of oil $(0.9788$ $\mathrm{g} / \mathrm{ml})$ and Specific gravity of (0.9947). From the result obtained we conclude that $\mathrm{n}$-hexane is an effective solvent and soxhlet extraction is an effective extraction method for extraction of oil from Niger seed.
\end{abstract}

\section{INTRODUCTION}

Niger (Guizotia abyssinica) is an oil seed crop cultivated in Ethiopian and Indian. It constitutes about $50 \%$ of Ethiopian and 3\% of Indian oil seed production. In Ethiopia it is cultivated on water logged soils where most crops and all other oil seeds fail to grow and contributes a great deal soil conservation and land rehabilitation [1].

The genus guizotia consist of six species of which five including Niger, are native to the Ethiopian high lands. It is dicotyledonous herb, moderately to well branched and growth up to $2 \mathrm{~m}$ tall. The seed contains about $40 \%$ oil. Its fatty acid composition is $75 \%-80 \%$ linoleic acid, $7-8 \%$ palmitic and stearic acid,5-8\% oleic acid. The Indian types contain $20 \%$ oilic and $50 \%$ linoleic acid $[2,3]$. Niger seed is indigenous to Ethiopia where it is grown in rotation with cereals and pulses [4].

\subsection{Statement of the problem}

Ethiopia is confronted with the twin crises of shortage of edible oils and financial crises. This is because of edible oil are imported from outside by transporting long distance. Then to solve this problem producing edible oil from local oil seed is necessary. Ethiopia, endowed with diverse ecological varieties and enough fertile lands for growing different seed oils that have a great potential for edible oil production but it is not benefited from its wealthy. Therefore for this study Niger seed were selected for its oil content and physico-chemical parameters determination. 


\subsection{Objective of the study}

\subsubsection{General objective}

The general objective of this study is to determine the oil content and the physico- chemical parameters of oils extracted from Niger seed grown in Gamo gofa, southern Ethiopia.

\subsubsection{Specific objective}

- Extraction of the crude oil from Niger seed by maceration and soxhlet apparatus using nhexane and ethyl acetate as an extracting solvent.

- Determine and compare the amount of oil extracted from Niger seed by maceration and soxhlet apparatus using n-hexane and ethyl acetate as an extracting solvent.

- Determine the physicochemical properties of crude oil extracted such as:- acid value, density, saponification value and peroxide value.

\section{MATERIALS AND METHODS}

\subsection{Materials}

The Niger seed were collected from Gamo goffa in Ethiopia to extracted oil from it using n- hexane and ethyl acetate an extracting solvents.

\subsection{Chemical and Reagents}

n- hexane, ethyl acetate, sodium thiosulfate, phenolphthalein and potassium hydroxide.

\subsection{Instrumentations}

Soxhlet apparatus, rotary evaporator, hot plate, round bottom flask, funnel, beaker, measuring cylinder, volumetric flask, mortar and pestle was used.

\subsection{Extraction of oil from Niger seed via soxhlet apparatus}

Oven dried of Niger seed will be grounded in to powder by using pestle and mortar. After that 70 gram of the sample will be loaded in to thimble in soxhlet apparatus. Next to that extraction was carried out using $338 \mathrm{ml}$ normal hexane $68^{\circ} \mathrm{c}$ (boiling temperature of hexane) for $24 \mathrm{hr}$ in electrical heater. The mixture of the extracted oil and the hexane was separated by rotary evaporator and by simple distillation, and percentage of the oil was calculated by the following formula;-

$\%$ oil $=$ mass of oil $* 100 /$ sample

\subsection{Parameters of the oil measured during the experiment}

\subsubsection{Determination of moisture content}

10 gram of samples was measured and oven dried at $105^{\circ} \mathrm{c}$ for 8 hours cooled desiccators and reweighed to determine the weight lost. After that the moisture content the kernel was determine the test was replicated three times and the average moisture content in the niger kernel was calculated by using the following formula;-

$\%$ Moisture content $=$ mass of water lost*100/Mass of kernel before oven dried

Finally the dried kernel was bagged in plastic container and stored for subsequent use.

\subsubsection{Oil extraction and determination of the percentage of the oil extracted}

The cleaned kernels were grounded in to powder by using pestle and mortar after that the 70 grams of grounded kernel was loaded in to thimble in soxhlet apparatus and extraction was carried out by using $332 \mathrm{ml}$ normal hexane at $68{ }^{\circ} \mathrm{C}$ by (boiling temperature of hexane) for 9 hour in an electrical heater. After that moisture of the extracted oil and hexane was separated by simple distillation and the percentage of the oil was calculated by the following formula;- $\%$ oil=Mass 0 oil $* \mathbf{1 0 0 / M a s s}$ of kernel

\subsubsection{Determination of the physicochemical properties of the extracted Niger seed oil}

The physicochemical properties of extracted oil such as Density, Viscosity, Acidic value, free fatty acid, Peroxide and saponification value were determined.

\subsubsection{Determination of density and specific gravity}

Density bottle was used to determining the density of the oil. A cleaned and dried empty bottle of $25 \mathrm{ml}\left(\mathrm{V}_{0}\right)$ capacity was weighed $\left(\mathrm{M}_{0}\right)$ and then filled with the oil, and reweighed to give $\left(\mathrm{M}_{1}\right)$. The oil was substituted with water after washing and drying the bottle and weighed to give $\left(\mathrm{M}_{2}\right)$. The 
density and the specific gravity of the sample (oil) was calculated according to the following equation;- Density of oil=Mass of oil/Volume of oil $=\mathbf{M}_{1}-\mathbf{M 0} / \mathbf{V}_{0}$

Specific gravity of oil=Density of oil/Density of

$$
=\mathrm{M}_{1}-\mathrm{M}_{0} / \mathrm{M}_{2}-\mathrm{M}_{0}
$$

Where $\mathrm{M}_{0}=$ Mass of empty bottle, $\quad \mathrm{M}_{1}=$ Mass of bottle + oil

$\mathrm{M}_{2}=$ Mass of bottle + water, $\mathrm{V}_{0}=$ Volume of bottle

\subsubsection{Determination of acid value}

5 gram of oil was added in to a $250 \mathrm{ml}$ conical flask and few drop of phenolphthalein were added to it. Then the mixture was titrated with $0.1 \mathrm{NKOH}$ to the end point with constant shaking until a dark pink color was observed and the volume of $0.1 \mathrm{NKOH}$ were note. The acidic value and free fatty acid of the oil was calculated by the following formula;-

Acidic value $=56.1 * \mathrm{~N} * \mathrm{~V} / \mathrm{m}$

Where $\mathrm{V}=$ the volume of $0.1 \mathrm{NKOH}$ use for titration

$\mathrm{N}=$ Normality of $0.1 \mathrm{~N} \mathrm{KOH}, \mathrm{m}=$ Mass of the oil use

The free fatty acid of the oil was calculated from the acid value using the following equation;-

Acid value $=\%$ free fatty acid $* 2$ then $\%$ free fatty acid $=$ acid value $/ 2$

\subsubsection{Saponification value determination}

A 2 grams sample was weighed in to a conical flask after that $25 \mathrm{ml}$ of $0.1 \mathrm{~N}$ ethanolic $\mathrm{KOH}$ was added. The content mixture were constantly stirred and allowed to boil gently for 1 hour. Reflex condenser was placed on the flask containing the mixture. A few drops of phenolphthalein indicator was added to the warm solution and then titrated with $0.43 \mathrm{~N} \mathrm{HCl}$ to the end point until the pink color of the indicator just disappeared. The same procedure was used for blank. The saponification value is determined by the following equation;-

$\mathrm{SV}=56.1 \mathrm{~N}\left(\mathrm{~V}_{\mathrm{b}}-\mathrm{V}_{\mathrm{a}}\right) / \mathrm{W}$

Where $\mathrm{W}=$ weight of oil used, $\quad \mathrm{N}=$ normality of $\mathrm{HCl}$ solution

$\mathrm{V}_{\mathrm{a}}=$ volume of $\mathrm{HCl}$ solution used in the test, $\mathrm{V}_{\mathrm{b}}=$ volume of $\mathrm{HCl}$ solution used in blank

\subsubsection{Determination of peroxide}

To 1 gram of oil sample, 2 gram of potassium iodide and $20 \mathrm{ml}$ solvent mixture (glacial acetic acid, chloroform 2:1 by volume) is mixed and boil for one minute. The hot solution was pour in to a flask containing $20 \mathrm{ml} \mathrm{5 \%}$ potassium iodide. A few drops of starch solution were added to the mixture and the latter was titrate with $0.025 \mathrm{~N} \mathrm{Na}_{2} \mathrm{~S}_{2} \mathrm{O}_{3}$ and the per oxide value determine the following equation;-

$\mathrm{PV}=\mathrm{S} * \mathrm{~N}^{*} 10^{3} / \mathrm{W}$ Where $\mathrm{S}=\mathrm{Ml}$ of $\mathrm{Na}_{2} \mathrm{~S}_{2} \mathrm{O}_{3}, \quad \mathrm{~N}=$ Normality of $\mathrm{Na}_{2} \mathrm{~S}_{2} \mathrm{O}_{3}, \quad \mathrm{~W}=$ Weight of sample $(\mathrm{g})$

\section{RESULT AND DISCUSSION}

\subsection{Amount of oil extracted by maceration and soxhlet apparatus}

The amount of oil extracted from Niger seed by maceration and soxhlet extraction was described in the following table.

Table 1: Extraction of oil from Niger seed

\begin{tabular}{|l|l|l|l|}
\hline Type of Solvents used & Method of extraction & $\%$ of oil & Duration extraction time \\
\hline \multirow{2}{*}{ n-hexane } & Maceration & 23.45 & \multirow{3}{*}{ 9 hours } \\
\cline { 2 - 3 } & Soxhlet & 33.02 & \multirow{2}{*}{} \\
\hline \multirow{2}{*}{ Ethyl acetate } & Maceration & 21.35 & \\
\cline { 2 - 3 } & Soxhlet & 22.7 & \\
\hline
\end{tabular}

In this study the oil extracted by using soxhlet apparatus and n-hexane $(23.45 \& 33.02 \%)$ as a solvent was higher in amount than that of the oil extracted by using ethyl acetate $(21.35 \& 22.7 \%)$ as a solvent. This is because n-hexane is highly non polar than ethyl acetate and the extracted oil is also highly non polar then this is due to like dissolve like principle. In addition to this the amount of 
oil extracted by Soxhlet $(22.7 \%$ \& $33.02 \%)$ is higher than the oil extracted by maceration $(21.35 \%$ \& $23.45 \%$ ) in n-hexane \& ethyl acetate respectively. This is because of Soxhlet extraction is a hot extraction while maceration is a cold extraction.

Table 2: Physichemical characters of the extracted oil

\begin{tabular}{|l|l|}
\hline Properties & values \\
\hline Color & Pale-yellow \\
\hline Dynamic Viscosity $(\mathrm{kg} / \mathrm{ms})$ & 0.05491 \\
\hline Kinematic viscosity $\left(\mathrm{m}^{2} / \mathrm{s}\right)$ & 0.561 \\
\hline Density of water $(\mathrm{g} / \mathrm{ml})$ & 0.984 \\
\hline Density of oil $(\mathrm{g} / \mathrm{ml})$ & 0.9788 \\
\hline Specific gravity & 0.9947 \\
\hline Acid value $(\mathrm{meq} \mathrm{KOH} / \mathrm{g})$ & 1.7391 \\
\hline$\%$ Free fatty acid $(\mathrm{meq} / \mathrm{g})$ & 0.86955 \\
\hline Saponification value $(\mathrm{mg} \mathrm{HCl} / \mathrm{g})$ & 6.0308 \\
\hline Peroxide value $(\mathrm{eq} / \mathrm{g})$ & 0.1213 \\
\hline
\end{tabular}

\section{CONCLUSION}

A soxhlet and maceration extractions were used for extraction of the oil. The solvents used for both extractions were n-hexane and ethyl acetate for 9 hours. The main reason two different types of solvents and two different type of extraction methods used in this project were to check which type of solvent and extraction method were effective for extraction of oil from Niger seed. From both extraction methods the oil was separated from the solvents by simple distillation. The oil extracted by using soxhlet apparatus and n-hexane $(23.45 \& 33.02 \%)$ as a solvent was higher in amount than that of the oil extracted by using ethyl acetate $(21.35 \& 22.7 \%)$ as a solvent. This is because n-hexane is highly non polar than ethyl acetate and the extracted oil is also highly non polar then this is due to like dissolve like principle. In addition to this the amount of oil extracted by Soxhlet $(22.7 \%$ \& $33.02 \%)$ is higher than the oil extracted by maceration $(21.35 \% \& 23.45 \%)$ in $n-$ hexane \& ethyl acetate respectively. This is because of Soxhlet extraction is a hot extraction while maceration is a cold extraction.

The physico-chemical parameters of the seed and oil were determined and the result shows that moisture content of the seed was (8.3\%) and acid value of the oil (1.7391), saponification value $(6.0308)$, Kinematic viscosity $\left(0.561 \mathrm{~m}^{2} / \mathrm{s}\right)$, Density of oil $(0.9788 \mathrm{~g} / \mathrm{ml})$ and Specific gravity of (0.9947). From the result obtained we conclude that $n$-hexane is an effective solvent and soxhlet extraction is an effective extraction method for extraction of oil from Niger seed.

\section{Reference}

[1] Abebe, M. 1975.Ecophysiology of noog (Guizotiaabyssinica class).phD Thesis. University of California.

[2] Abebe,D.1992. Ethiopia's oil seed genetic resources.Pp.13- 23 in oil seed Research and development in Ethiopia. Processing of the first national oil seed work shop, 3-5 December 1991, Addis Abeba.

[3] Baagoe, J. 1974.The genus Guizotia (compositae). A taxonomic revision. Bot. Tidsskritt 69:139.

[4] Belayneh, H. 1987. Determination optimum harvesting stage for Niger (Guizotia abyssinica class). Ethiop.J.Agric.Sci.9:83-94. 